\title{
Mortalidad Perinatal en la Operación Cesárea
}

\author{
Dr. Ernesto Delgado Caiderón
}

Del Instituto Materno Infantil - Bogotá

El presente trabajo fue realizado en el Instituto de Protección Materno Infantil. Se hizo una revisión de la mortalidad perinatal en las operaciones cesáreas practicadas durante los años de 1959 y 1960.

Es siempre un capítulo de actualidad el relacionado con este tipo de mortalidad, por cuanto las causas determinantes en su mayoría, permanecen presentes. Algunas de ellas no son en cierto modo evitables o prevenibles pero sin duda alguna, un estudio más cuidadoso de cada paciente puede inducirnos a pensar en una posible complicación que repercute directamente sobre el feto, como consecuencia de un trabajo de parto mal conducido, bien por el abuso de la analgesia come de los ocitócicos y el mal control de las pacientes.

Creo positivamente que, aunque se hayan hecho estudios exhaustivos sobre las causas de la mortalidad perinatal especialmente sobre la anoxia fetal, siempre será de la mayor importancia la consideración de este tema.

Por lo menos teóricamente, se puede decir que la cesárea debe ser, para la mortalidad fetal, un factor traumatizante menos importante que el parto espontáneo y el intervenido. En el curso de un trabajo de parto, durante los fenómenos de encajamiento y descenso de la presentación, se ejercen sobre el feto una serie de fuerzas opuestas, como son, por una parte, las contracciones uterinas, y por la otra, la resistencia que pueda presentar al progreso de la presentación tantc el anillo óseo de la pelvis como las partes blandas del tracto genital. Estas fuerzas opuestas determinan a veces compresiones demasiado traumatizantes para la cabeza fetal, que pueden iscr la causa de hemorragias meníngeas y 
las diferentes manifestaciones de sufrimiento fetal; si a esto se añaden los partos instrumentales y el trabajo prolongado, se puede pensar en los efectos sobre el feto.

En cambio durante la cesárea oportuna el traumatismo sobre el feto es menor. No se descartan del todo los efectos nocivos, ya que hay casos en que la extracción resulta laboriosa, con las consecuencias antes anotadas. Además, ocurre a veces que la intervención se practica después de un trabajo más o menos largo, o con sufrimiento fetal avanzado, los cuales determinan por sí solos la mortalidad fetal, sin que ésta pueda atribuírse a la cesárea, sino a la indecisión para practicarla oportunamente.

Durante los años de 1959 y 1960 sobre un total de 22.564 partos, se practicaron 1.012 cesáreas con un índice del $4.66 \%$. La mortalidad perinatal en las cesáreas durante los dos años fue del $5.39 \%$ del total de 1.012 operaciones.

Las causas de las muertes neonatales fueron:

No de Casos

Anoxia por placenta previa 8

Anoxia por sufrimiento fetal (causas varias)

Bronconeumonía

3

5

Sepsis

Neumonía

3

3

Anomalías congénitas múltiples

2

Prematurez

2

Inmadurez

Anoxia por hemorragia cerebral

Eritroblastosis fetal

Causa desconocida

Las causas de muerte fetal ante-partum fueron:

Placenta previa

Abruptio placentae

Prolapso del cordón

Causa desconocida

Proporcionalmente ha habido un aumento tanto de la operación cesárea como de la mortalidad perinatal derivado del crecido número de paciertes que en la actualidad acuden al servicio hospitalario. 
En el año de 1956 se obtuvieron los siguientes datos sobre la mortalidad perinatal:

Neonatales

№ de Casos

Anoxia por hemorragia intracraneana

2

Anoxia por placenta previa

Anoxia por sufrimiento fetal in útero, causas varias 2

Malformaciones congénitas

Neumonía

Bronconeumonía

Acidosis

Prematurez

Causa desconocida

Mortinatos

Placenta previa

Abruptio placentae

Muerte materna 3

Retención de cabeza 1

Prematurez

Procidencia de cordón

Ruptura uterina

Causa desconocida

En algunos casos la cesárea se practicó a sabiendas de que el feto estaba muerto. Los índices más altos en este grupo de mortalidad intrauterina corresponden a la placenta previa y al abruptio placentae.

La causa más importante de la mortalidad perinatal es la anoxia.

\section{ANOXIA}

Cuando por cualquier circunstancia la cantidad de oxígeno es insuficiente para satisfacer las necesidades normales de las células, se establece un estado de anoxia.

Con la modificación de los métodos obstétricos, se ha disminuído el traumatismo obstétrico, pero también en virtud de esos métodos a causa de los sedantes, analgésicos y anestésicos, se ha aumentado la anoxia. 
Se ha investigado la frecuencia de la anoxia en el parto, las causas de anoxia en general y en especial, las que corresponden al recién nacido, haciendo su clasificación, estudiando la relación de la anoxia con la mortalidad neonatal, el tratamiento y los resultados obtenidos, ya que la mortalidad neonatal representa cifras importantes dentro de la mortalidad infantil general y la hipoxia representa uno de sus principales factores.

Definición de la Anoxia. - Es la insuficiencia de oxígeno para satisfacer las necesidades normales de las células.

Anoxemia. - Significa ausencia del oxígeno en la sangre.

Fisiopatología de la Anoxia. - Un recién nacido cuyo sistema nervioso es normal, debe respirar dentro del primero o segundo minuto que sigue a la separación completa de la madre, siendo ésto la continuación y en mayor escala, en medio aéreo de los movimientos respiratorios norrnales realizados en el útero.

Para realizarse la respiración extrauterina en medio aéreo, los movimientos respiratorıos se continúan.

Schwartz, fué el primero en indicar como causa del primer movimiento respiratorio del niño. la excitación del centro respiratorio del bulbo como consecuencia de modificaciones del intercambio gaseoso entre la madre y el niño. Swiefel, demostró que la sangre de la vena umbilical contiene más oxígeno que la de las arterias umbilicales y que ésta contiene más anhídrido carbónico. Algunos autores afirman que el intercambio gaseoso en el interior del útero, es menor que el de la vida extrauterina. Otros niegan la importancia del intercambio gaseoso y admiten como iniciadores de la respiración, las excitaciones externas, el enfriamiento, los traumatismos mecánicos, etc. Hay quienes niegan la teoría de la excitación externa y señalan como mecanismo la distensión del tórax que se halla comprimido en el canal del parto. Esquemáticamente puede decirse que el centro respiratorio en condiciones normales, responde a estímulos sensoriales (táctiles y térmicos), así como químicos (gas carbónico) y pone en marcha los músculos de la respiración. El comienzo de la respiración del recién nacido puede corresponder a dos variedades:

$1^{\text {o }}$ - Con un mecanismo intacto del sistema nervioso central, la respiración comienza $\mathrm{po}^{-*}$ un movimiento rítmico de inspiración y espiración acentuado po: e' llan o Estics niños responden muy 
bien a los estímulos cutáneos y propioceptivos y es muy poco lo que hay que hacer para reanimarlos.

$2^{0}$ - Mecanismo del sistema nervioso central alterado por efectos de la anestesia, anoxia, sedantes, trauma obstétrico, etc. El comienzo de la respiración es demorado y se presentan series de bloqueos irregulares sin un verdadero ritmo respiratorio, no hay respuesta a los estímulos cutáneos. Estos niños son los que necesitan procedimientos para restablecer la respiración.

Las alteraciones respiratorias y circulatorias dañan los órganos más vulnerables a la hipoxia, como son los centros nerviosos y el corazón. Cuando el centro respiratorio de un niño está lesionado por traumatismo (hemorragia), por hipoxia (gas carbónico) o lesionado por drogas (analgésicos, anestésicos), es incapaz de responder a los estímulos sensoriales y entra en juego el estímulo químico del gas carbónico acumulado por falta de respiración. Es ésta una situación de emergencia en que la respiración que se obtiene no es normal, sino muy irregular y en forma de boqueo. Si la concentración de gas carbónico circulante es excesiva, el centro respiratorio no responde más y la apnea es completa. En estas condiciones el único recurso es llevar oxígeno al centro respiratorio y a los órganos vitales.

Causas de la apnea neonatal. - Los factores que actúan sobre el centro respiratorio y que pueden producir apnea neonatal son:

\section{I - Químicos:}

a) Drogas: sedantes, ánalgésicos, anestésicos, oxitócicos, venenos, sulfas.

b) Anoxia : 1 - De origen materno (hipoxia materna, hemorragia y shock, enfermedad cardio-respiratoria, shock, toxemia, diabetes, hipotensión, tetanización uterina).

2 - De orizan placentario y funicular (infarto, enfermedad hemolítica, sífilis, envejecimiento placentario, desprendimiento prematuro, placenta previa, prolapso y circulares del cordón, compresiones funiculares en el parto de pelvis).

3 - De origen fetal (analgésicos y anestésicos que atravesaron la placenta, shock por distocia, hemorragia intracraneana, hemorragia del lado fetal de la placenta, obstrucción respiratoria, 
anomalías congénitas cardiovasculares o del sistema nervioso central, hernia diafragmática, enfermedad hemolítica, membrana hialina, inmadurez del aparato muscular respiratorio o de los pulmones.

\section{II - Factores Traumáticos:}

Parto de pelvis, parto prematuro, uso inadecuado de fórceps. III - Factores Infecciosos:

Parto prolongado, ruptura prematura de la bolsa, infección materna.

Clasificación de la Anoxia. - Según las causas que puedan provocar la anoxia, se ha dividido en 4 tipos:

1 - Anoxia anóxica

2 - Anoxia anémica.

3 - Anoxia por éstasis.

4 - Anoxia histotóxica.

La primera se debe a una insuficiente oxigenación de la sangre en los pulmones.

La segunda a una disminución de capacidad transportadora de oxígeno por parte de la sangre.

La tercera a alteraciones circulatorias que dificultan la llegada de sangre oxigenada a los capilares.

La cuarta a mecanismos tóxicos que dificultan el aprovechamiento del oxígeno por los tejidos.

\section{HIPOXIA FETAL}

Etiología. - Hay multitud de causas de hipoxia fetal, muchas de las cuales no son prevenibles. Ejemplo: desprendimiento prematuro de la placenta, placenta previa, brevedad del cordón, nudo verdadero del cordón, circulares y prolapso del cordón, ruptura prematura de la membrana, etc. En estos casos se debe evitar la administración en dosis excesivas de sedantes, los cuales podrán hacer descender la concentración arterial del oxígeno, que de por sí es solo el $50 \%$ de la capacidad de oxigenación del feto.

Referente a la anestesia, el ideal desde el punto de vista de la oxigenación fetal es el de la anestesia regional en sus varias 
formas, por ejemplo: anestesia raquídea, anestesia caudal continua, bloqueo en silla, bloqueo pudendo.

A pesar de estas precauciones, el déficit de oxígeno se presenta frecuentemente en el parto. Afortunadamente la hipoxia fetal, si se trata en forma oportuna y adecuada, responde rápidamente a los métodos de reanimación. La mayoría de las veces la hipoxia causa alteración de los ruidos cardíacos fetales tanto en su frecuencia, como en la regularidad e intensidad de los mismos (sufrimiento fetal).

La anoxia intrauterina corresponde a interferencias de la oxigenación de la sangre en la placenta. Hay tres casos:

a) Separación de las vellosidades coriales como ocurre en el abruptio placentae. Es el caso que se presenta frecuentemente en toxémicas y eclámpticas.

En el caso del abruptio placentae el desprendimiento o sepa. ración de la placenta de la pared uterina producirá anoxia, la cual depende del grado del desprendimiento; si es muy amplio sobrevendrá la muerte in útero. Si el desprendimiento es marginal, no habrá hemorragia aparente, pero sí un hematoma retroplacentario. En el abruptio la hemorragia se hace a expensas de la sangre materna, pues ésta escapa de los sinusoides maternos. La circulación fetal sigue intacta mientras la placenta no se lesione en el parto. La anemia de estos niños puede deberse a retención de sangre en la placenta por falta de expresión uterina durante la contracción uterina.

Puede haber circulares o nudos sin que éstos impidan la circulación; pero si se llega a tensionar el cordón por lo cual se reduce el calibre de los vasos, impedirá el paso de la sangre o por lo menos su disminución. Ocurre lo mismo en los prolapsos del cordón al comprimirse éste sobre la pelvis. En este caso no habrá paso de sangre con lo cual sobreviene la muerte del feto. En el caso de retención de cabeza última, hay anoxia por compresión del cordón entre la cabeza y la pelvis de la madre. La anoxia también puede presentarse cuando se comprime la placenta entre el cuerpo fetal y la pared uterina.

b) Disminución del oxígeno en la sangre materna. Ocurre durante la anestesia general. 
c) La sangre no circula normalmente hacia la placenta o dicha circulación se hace en forma lenta, ejemplo: los casos de shock o por ruptura uterina.

En relación con el tema de la infección amniótica y la infección fetal, la reciente literatura de los Estados Unidos trae algunos puntos interesantes. Muchos de los autores creen que todas las neumonías que ocurern en los tres primeros días siguientes al nacimiento tienen un origen intrauterino. Así, gracias a una infección ascendente, los agentes venidos de los órganos genitales pueden penetrar en el interior del saco amniótico a través de las membranas rotas para provocar la infección del líquido, el cual es aspirado o deglutido por el feto. Pero las bacterias también pueden invadir el organismo fetal a través de la circulación placentaria, produciendo una bacteremia o una peritonitis en el feto.

Edith Potter hizo un análisis de la incidencia de la neumonía fetal en el Chicago Lying. In Hospital desde 1931 hasta 1956. Encontró los siguientes índices de neumonía fetal congénita: de 1931 a 1941 , el $1,8 \%$; de 1951 a 1956 , el $0.9 \%$. Hubo pues una notoria disminución en la incidencia de este tipo de infección.

Arey en 1947 hizo algunas observaciones post-mortem en 22 niños prematuros. Encontró un proceso de bronconeumonía en seis casos, con evidencia de aspiración en tres de ellos. El autor de este estudio sostiene que las bacterias halladas en el líquido aspirado de la nariz y la boca de los recién nacidos son similares a las encontradas en la vagina de las madres. Esto explica suficientemente el mecanismo de la infección del tracto respiratorio y digestivo, de los senos paranasales y el oído medio de los recién nacidos. La diferencia entre la simple aspiración del exudado amniótico y la verdadera neumonía fué descrita primeramente por Sorba, en estudios hechos en autopsias del aparato bronco-alveolar, demostrando la presencia de elementos de líquido amniótico aspirado, mezclados con un número variable de leucocitos polimorfonucleares multilobulados y degenerados. Sin embargo, no encontró una franca reacción fetal, presumiéndose que la muerte neonatal fue causada por una obstrucción respiratoria o una aspiración masiva de vernix caseoso. En la neumonía franca en cambio, hay una verdadera reacción fetal (leocopedesis) y las lesiones pueden asumir las características de una bronconeumonía. Las 
alteraciones de una neumonía producida por infección experimental del líquido amniótico son similares. Según los autores, en la mayoría de los casos de neumonía es fácil demostrar el origen broncogénico de la infección, por el hallazgo de leucocitos multinucleares viejos y degenerados tanto en los bronquios como en los alvéolos, idénticos a los encontrados en el líquido amniótico infectado y a los hallados en casos de simple aspiración de exudado amniótico. En el material analizado, se halló la evidencia de aspiración del contenido amniótico en todos los casos de neumonía en los fetos prematuros y en los recién nacidos muertos en las primeras 24 horas.

Esto indica, en términos generales, que el sufrimiento fetal es un factor importante en la contaminación del tracto broncoalveolar, toda vez que induce a aumentar los movimientos respiratorios intrauterinos.

\section{MATERIAL}

La base de este estudio la constituyó el análisis de 307 muertes perinatales ocurridas en el lapso de 1948 a 1953, incluyendo 113 partos con feto vivo. Las placentas fueron examinadas por lo menos en 253 casos. En uno de éstos se encontró una asociación entre placentitis y neumonía fetal. La incidencia de la neumonía fetal fue de $0.06 \%$ en todos los partos, y el $5 \%$ de todos los nacidos vivos que murieron en las primeras 24 horas.

Existen sin embargo dificultades para poder establecer la relación entre la neumonía y las muertes fetales, puesto que las causas de las mismas, no están claramente establecidas en muchos casos a la cabeza de los cuales se hallan los nacidos muertos. Es muy dudoso que una falta de consolidación de los pulmones de los nacidos muertos sea la causa; pero parece muy razonable pensar que la neumonía puede ser la manifestación de una severa infección fetal que acompaña generalmente a una sepsis.

Sabida es la relación existente entre la infección amniótica, la morbilidad neonatal y los disturbios respiratorios. Las complicaciones clínicas asociadas con la aspiración del líquido amniótico infectado, y la neumonía congénita neonatal temprana (prematuridad, trabajo prolongado y complicado, ruptura prematura de las membranas) probablemente se presentan también en los casos de supervivencia con síntomas respiratorios presentes. 
Otro problema de importancia en el terreno de las infecciones neonatales es el de la gastroenteritis. La deglución del material amniótico infectado ocurre en la mayoría de los casos de infección amniótica. Entre los fetos sobrevivientes de las series analizadas, con pruebas de infección amniótica, dos casos presentaron una gastritis aguda y un tercer caso presentó una ileítis focal aguda con perforación o peritonitis temprana. La peritonitis bacteriana fetal ha sido descrita por H. Flamm y M. Staemmler. La gastritis y la enteritis son comunes en el primer día de vida, según W. A. Blanc.

En el curso de un estudio microscópico del contenido gástrico en 1.000 casos de recién nacidos, se halló una gran variedad de bacterias, $y$ en algunos se encontraron esporos de C. Albicans.

En relación con la sepsis congénita, es muy poco lo que se sabe actualmente sobre la incidencia y efecto letal. La morfología de una sepsis fetal fue descrita por Wohlwill y Bock. Ocasionalmente una lesión focal probablemente de origen hematógeno, se observa en los fetos viables.

Actualmente la pihemia es siempre postnatal y generalmente resulta de una flebitis de la vena umbilical.

\section{CONCLUSIONES}

$1^{\text {a }}$ - Se ha demostrado que la hipoxia y la patología pulmonar son las causas más frecuentes de morbi-mortalidad en el recién nacido y que de su adecuada prevención depende el futuro del niño.

$2^{\text {a }}$ - Las causas de hipoxia son a veces imprevisibles pero en gran parte se pueden prevenir con un estudio más cuidadoso de la madre durante el embarazo y principalmente durante el trabajo.

$3^{a}$ - Sin ser muy común, la neumonía congénita es la complicación más importante que resulta de la infección del líquido amniótico, según se ha podido observar en los recién nacidos. La incidencia de la neumonía es paralela a la de la ruptura prematura de las membranas, pero su asociación no es muy constante. En cambio, la asociación de neumonía con las lesiones placentarias provocadas por la infección amniótica, es verdaderamente constante. 
$4^{\text {a }}$ - El uso indiscriminado del Pitocín así como de la analgesia, aumenta la incidencia del irabajo complicado y la anoxia fetal. Afortunadamente en la actualidad tiende a mejorar este aspecto, con la estructuración de una verdadera escuela obstétrica.

$5^{\text {a }}$ - Es importante que toda Institución de Maternidad cuente con el mayor número posible de facilidades para la atención de los recién nacidos en especial los anóxicos.

$6^{\text {a }}$ - Los exámenes vaginales deben realizarse bajo las más estrictas normas de asepsia y no deben ser muy repetidos, porque pueden favorecer la infección.

\section{BIBLIOGRAFIA}

1 AHVEnAINEN E. J.: Asphysia Neonatorum. Ann. Med. Int. Fenniae 42 (supp. 18). 1. 1954.

2 BUDENSEN H. N. and Co. Progress in Reduction of Needless Neonatal deaths. J.A.M.A. 148, 11: 913. March. 1952.

3 GORDON, D. R. and BIRNBAUM. S. J.: "Intrapartum and puerperal infection". Clinical Obstetrics and Gynecology, 2: 693, 1959.

4 International Recomendations on definitions of, live birth and fetal death (PHS publication N. 39. National Office of Vital Statistics. Oct. 1950). Manual of the International Statistical Classification of Diseases, Injuries and causes of Death (Sixth revision; world health organization, 1948), Vol 1: 212.

5 LEE-GREENHILL: Principios y Práctica de Obstetricia. Accidentes del Feto; 8a Ed. II. 1947.

6 OBES POLLERI J. Y MATTEO A. Clasificación anatómica y etiopatogénica de las hemorragias intracraneanas del recién nacido. Revista Colombiana de Pediatría y Puericultura. Número Extraordinario. 116. Enero. 1952.

7 PLATA RUEDA ERNESTO. Mortalidad Neo Natal hospitalaria en Bogotá. Revista de la Sociedad Colombiana de Pediatría y Puericultura. 2á época. N. 5 Año XVI: y sig. Agosto 1958.

8 POTTER E. L.: Pathology of the fetus and the newborn. The Year Book Publishers; 54. 